Paper ID \#19192

\title{
Creating Pathways to Stackable Credentials in Robotics by Manufacturing a Community College and University Partnership - Year Two Progress
}

\author{
Mr. Mark Bradley Kinney, Bay de Noc Community College
}

Mark Kinney became the Dean for Business and Technology in July of 2012, but first came to Bay College as the Executive Director of Institutional Research and Effectiveness in February 2009. Prior to that, Mark served as the Dean for Computer Information Systems and Technology at Baker College of Cadillac and as the Chief Operating Officer and network administrator at Forest Area Federal Credit Union. He has taught a wide range of courses in the computer information systems discipline and holds certifications in both Microsoft Excel and Microsoft Access. Mark has a Master's in Business Administration with a concentration in Computer Information Systems from Baker College, as well as a Bachelor's in Business Leadership and an Associate's of Business from Baker College. Currently, Mark is completing his dissertation in fulfillment of the requirements of a Doctorate in Educational Leadership from Central Michigan University.

\section{Mr. Mark Highum, Bay de Noc Community College}

Mark Highum is currently the Division Chair for Technology at Bay College. He is the Lead Instructor for Mechatronics and Robotics Systems and also teaches courses in the Computer Network Systems and Security degree. Mark holds a Master's in Career and Technical Education (Highest Distinction) from Ferris State University, and a Bachelor's in Workforce Education and Development (Summa Cum Laude) from Southern Illinois University. Mark is a retired Chief Electronics Technician (Submarines) and served and taught as part of the Navy's Nuclear Power Program. Mark is active with SkillsUSA and has been on the National Education Team for Mechatronics since 2004.

\section{Prof. Aleksandr Sergeyev, Michigan Technological University}

Aleksandr Sergeyev is currently an Associate Professor in the Electrical Engineering Technology program in the School of Technology at Michigan Technological University. Dr. Aleksandr Sergeyev earned his bachelor degree in Electrical Engineering at Moscow University of Electronics and Automation in 1995. He obtained the Master degree in Physics from Michigan Technological University in 2004 and the $\mathrm{PhD}$ degree in Electrical Engineering from Michigan Technological University in 2007. Dr. Aleksandr Sergeyev's research interests include high energy laser propagation through the turbulent atmosphere, developing advanced control algorithms for wavefront sensing and mitigating effects of the turbulent atmosphere, digital inline holography, digital signal processing, and laser spectroscopy. Dr. Sergeyev is a member of ASEE, IEEE, SPIE and is actively involved in promoting engineering education.

\section{Prof. Scott A Kuhl, Michigan Technological University}

Scott Kuhl is an Associate Professor of Computer Science and an Adjunct Associate Professor of Cognitive \& Learning Sciences at Michigan Technological University. He received his Ph.D. in Computer Science from the University of Utah in 2009. He has been the faculty advisor for Husky Game Development Enterprise since Spring 2010. His research interests include immersive virtual environments, headmounted displays, and spatial perception. A link to his web page can be found at http://www.cs.mtu.edu/. 


\title{
Creating Pathways to Stackable Credentials in Robotics by Manufacturing a Community College and University Partnership - Year Two Progress
}

\begin{abstract}
In rural locales like Michigan's Upper Peninsula, students and employers alike can struggle in their search to find STEM-based educational opportunities or qualified graduates to fill open positions. Due to the diverse needs of the small employers found in such an area, Bay de Noc Community College quickly realized that creating a different degree for each industry need would be an unsustainable and unreasonable approach. Instead, a partnership was formed with Michigan Technological University to create highly customizable and stackable credentials in the fields of mechatronics, robotic systems, and electrical engineering technology. By codeveloping this curriculum and partnering on a number of grant applications to procure equipment, these two institutions have created replicable student pathways that not only meet local employer demand, but also give students numerous options for the type and timing of their educational progression.

Last year, representatives from the community college presented on this partnership at the annual ASEE conference in New Orleans to introduce their work to others in the hope that similar partnerships would result elsewhere in the country. With a full year of progress having now been made on this partnership, and with several students having already completed the certificate portion of the credential ladder, more information is now available in regards to strategies that appear to be working, others that do not, and some initial data analysis that has been conducted. Furthermore, non-credit workshops have since been developed and offered to other faculty of higher education, K-12 students, and K-12 teachers. A new robotic simulation software has also been developed to aid in instruction, which will be demonstrated to conference session attendees. Lastly, a fully-functioning mechatronics and robotic systems lab at the community college has been created, largely through the purchase of grant-funded equipment. These initial lessons learned and the progress made into year two of the grant represents important information to share with other colleges and universities who might also benefit from forming such a partnership in their area.
\end{abstract}

\section{Introduction}

In the Upper Peninsula of Michigan, colloquially known as the U.P., postsecondary educational opportunities are somewhat limited. The U.P. is 16,538 square miles, making it larger than Massachusetts, Connecticut, Delaware, and Rhode Island combined, but is served by only two community colleges ${ }^{1}$. Despite its large size, however, the U.P. has a population of only about 300,000 people $^{1}$. This means that the land itself represents $29 \%$ of Michigan's total area, but only $3.3 \%$ of its population ${ }^{2}$. While this low population density makes for beautiful countryside and bountiful outdoor recreational opportunities, it can also be challenging for both prospective students looking for an education and employers in search of new talent.

Serving the south-central portion of the U.P. is one of the region's two public community colleges. Officially titled Bay de Noc Community College, but commonly referred to simply as Bay College, this small institution of just over 1,800 students offers a wide variety of programs 
designed to either help students transfer to a university or enter the workforce directly. Founded in 1962, Bay College now offers programs in welding, water resource management, computer network systems and security, geographic information systems, business, office information systems, criminal justice, early childhood education, automotive technology, and many others. Each of these occupational programs were specifically chosen due to their direct connection to available jobs in the community and the surrounding region. By working closely with area employers, Bay College faculty and administration have a long history of identifying talent needs and developing relevant academic programming in response.

In recent years, however, a challenge seemed to present itself. Employers frequently called for qualified graduates in the field of advanced manufacturing, yet there seemed to be no consistency between employers in the specific skill sets being sought. One employer would talk of the need for new employees possessing a knowledge of electricity, while another desired hydraulics and pneumatics. Still others had moved on towards automation technologies and desired graduates with entry-level skills in robotics. Even within other industries, such as those typically targeted by the water resource management program, employers were asking for new skill sets in areas like process control, as well as supervisory control and data acquisition (SCADA). Despite the obvious need for qualified graduates entering these industries, Bay College could not possibly support programs in each of these areas due to its small size and limited resources. Thus, for years, the requests of these employers went unmet.

It was not until October of 2013 that an idea for a potential solution began to form. During a visit to Michigan Technological University in Houghton, MI, the dean for the business and technology programs at Bay College, Mark Kinney, met with two Michigan Tech University faculty members who had been contracted to perform some work under Bay College's recently awarded grant from the Trade Adjustment Assistance Community College and Career Training (TAACCCT) program under the Department of Labor. One of these faculty members was the Associate Professor in the Electrical Engineering Technology (EET) program at Michigan University, Aleksandr Sergeyev. While he provided a tour of the EET lab, he described a grant opportunity that might allow Bay College to not only obtain much of the equipment they would need to create an academic program designed to meet their area employers' advanced manufacturing needs, but could also be used to create a partnership between the two schools that would lead to coordinated curriculum and an articulation agreement between Bay College's program and that of Michigan Tech University. A year later that grant application was written and subsequently funded, allowing the two schools to pursue their development of a pathway to stackable credentials in robotics.

That partnership has now been in effect for nearly two years, providing the two schools with plenty of opportunities to learn about the practices and strategies that seem to work well, learn about those that are to be avoided, and develop their academic programs, facilities, and an articulation agreement to make their original vision a reality. Furthermore, the institutions have managed to develop new robotics simulation software to aid in the training of both students and industry partners, and have offered non-credit workshops to other educators and industry personnel. These successes and failures are detailed in the following sections, providing an opportunity for institutions looking to form similar partnerships to learn from the accomplishments and mistakes of others. 


\section{An Overview of the Program}

Even with grant funding, creating separate academic programs to meet each of the diverse requests from area employers was impractical. Instead, Bay College and Michigan Tech University aimed to create a single program that contained elements of each request. For instance, rather than creating an entire program surrounding the need for manufacturers with an electrical background, and yet another program focusing on hydraulics and pneumatics, a single program would be created that included introductory coursework in each of these areas and more. Under this model, students could get a single certificate or an associate degree and obtain employment in a variety of industries. Furthermore, individual courses could then be integrated into other academic programs where those skills were being requested, such as including a basic process control course in the water resource management program.

Since certain industry positions required only entry level skills, while others required a greater depth or breadth of knowledge and abilities, a stackable credentials model was used. Under this model, students can earn a certificate in mechatronics, which is a one-year program containing a variety of introductory courses in several advanced manufacturing fields. Students can then either enter the workforce directly or can stack an associate degree on top of their certificate by extending their studies for another year, thereby gaining additional training in robotics and automation technologies, as well as general education coursework. At this point, students once again have the option of entering the workforce directly or, thanks to the articulation agreement, transferring their associate degree to Michigan Tech University's EET bachelor degree program. The program thus has three separate credentials that can be stacked atop each other either during a student's initial entry into college or as they decide to pursue additional education after gaining direct experience in the workforce.

In addition to the development of academic programs, several other educational options were also created as part of this partnership. The first of these is to provide stand-alone, non-credit workshops to train and certify students from other institutions, industry representatives, and displaced workers. Workshops have also been created to train educators at both the K-12 and postsecondary levels on the use of robotic arms and the role the field of robotics plays in science, technology, engineering, and math (STEM) education. This activity is aimed at broadening the scope of the project beyond just Bay College and Michigan Tech University through improving the quality of industrial robotics education at other area institutions. Thanks to the attainment of certified education training by Bay College's full-time faculty member overseeing the program, Mark Highum, Bay College and Michigan Tech University will also now be able to offer reciprocal certification opportunities to attendees of these events. Lastly, robotic simulation software - titled RobotRun - has been developed to assist students in learning the basics of how to program robotic arms.

\section{Initial Results of Academic Programming}

After meeting with area employers to assess their needs, as well as pulling together an advisory board of local experts, curriculum was developed for a mechatronics certificate program and submitted to the Bay College curriculum committee in the fall of 2014 and first offered to 


\begin{tabular}{|c|c|c|c|c|c|}
\hline \multicolumn{3}{|c|}{ Requirements - Min 24 credits } & \multicolumn{3}{|c|}{ Suggested Sequences Per Semester } \\
\hline ELEC-130 & Circuit Fundamentals I & 4 & \multirow{2}{*}{\multicolumn{2}{|c|}{ First Semester }} & $\mathrm{Cr} / \mathrm{Ct}$ \\
\hline ELEC-180 & Electrical Machinery and Controls & 4 & & & \\
\hline ELEC-285 & Fluid Power & 4 & ELEC-130 & Circuit Fundamentals I & $4 / 4$ \\
\hline \multirow{3}{*}{$X X X X-X X X$} & Approved Electives & 12 & ELEC-285 & Fluid Power & $4 / 4$ \\
\hline & & & $X X X X-X X X$ & Elective & $X / X$ \\
\hline & Approved Electives & & & & \\
\hline ELEC-145 & Basic Process Control & 4 & \multirow{2}{*}{\multicolumn{2}{|c|}{ Second Semester }} & $12 / 12$ \\
\hline ELEC -290 & Introduction to Programmable & 4 & & & \\
\hline & Logic Controllers & & $\begin{array}{l}E L E C-180 \\
X X Y X X X X\end{array}$ & Electrical Machinery and Controls & $4 / 4$ \\
\hline MATH-102 & Introduction to Technical Math & 4 & 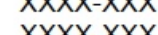 & Elective & 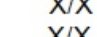 \\
\hline TECH-100 & Basic Machine Tool Operation & 4 & $x \times x x-x \times x$ & Elective & $\mathrm{X} / \mathrm{X}$ \\
\hline TECH-101 & Blueprint Reading & 2 & & & $12 / 12$ \\
\hline TECH-105 & Materials of Industry & 4 & & & \\
\hline WELD-110 & $\begin{array}{l}\text { Introduction to Oxygen-Fuel } \\
\text { Welding and Cutting }\end{array}$ & 3 & & & \\
\hline WELD-120 & ARC Welding & 4 & & & \\
\hline
\end{tabular}

Figure 1: Course Overview of the Mechatronics Certificate

students during the Fall 2015 semester (Figure 1). The number of students initially majoring in the program was around five, and several classes benefited from strong enrollment due to their inclusion in other degree programs on campus. For example, Circuit Fundamentals I had a total of 17 students enrolled during its initial offering due to its inclusion as an option within the water resource management program. This benefit of including courses across other degree programs was even more pronounced the following year, when two sections of Basic Process Control were required to support an enrollment of 37 students, again due to the course's inclusion in the water resource management program. This practice is an excellent example of a positive lesson learned that could be replicated at other colleges. By including even one or two courses in preestablished degree programs where content overlap exists, enrollment will be boosted in those courses, providing legitimacy and maybe even funding to the new program.

Another lesson learned during the startup of the mechatronics certificate was that the inclusion of electives provides students (and employers hiring students or sending workers for additional training) with the ability to tailor their studies to a specific industry or employer. During the first year of the certificate program, courses were mostly prescribed based on what the advisory board thought was needed in the industry. Those advisory board members recommended that Blueprint Reading be removed from the initial program proposal, since there were other skill sets that they thought would be more valuable. It quickly became apparent after meeting with other employers, however, that the skill of blueprint reading was actually a requirement in their industries, yet now it was no longer part of the mechatronics curriculum. Changes were therefore made to the certificate program to require only a basic list of courses, freeing up the rest of the program to be electives from an approved list (Figure 1 contains the complete list). Students can now target a specific industry or employer and choose the courses that are going to give them the greatest opportunity to obtain employment. One student may elect to take Blueprint Reading because their employer of choice requires it, while another one may focus instead on Basic Machine Tool Operation, since that skill is more desirable where they hope to work. This is another lesson learned during the first year of progress at Bay College. At the certificate level, where the total number of courses required is small, leave plenty of room for customization on the part of the student. 
Given the initial success of the certificate program, and keeping with the ultimate vision for creating stackable credentials, curriculum was also developed for a Mechatronics and Robotic Systems associate degree (Figure 2). Grant funds were used to purchase a total of six robotic arms, as well as a host of trainers relating to programmable logic controllers, pneumatics, hydraulics, mechanical and electrical systems, and more. A vacant room on campus was converted into a lab space (Figure 3) and the equipment installed. After successfully passing through Bay College's curriculum committee, the first associate degree level courses were offered during the Fall 2016 semester. Thanks in part to the steps taken to build the Mechatronics certificate, a total of 13 students are majoring in the Mechatronics and Robotic Systems associate degree during its second semester of operation. These students are in addition to another five who are majoring in the Mechatronics certificate, meaning a total of 18 students are currently signed up for the new degree program. Furthermore, three students graduated with the certificate during its first year of existence, with all three of them being retained in the associate degree program during the current academic year.

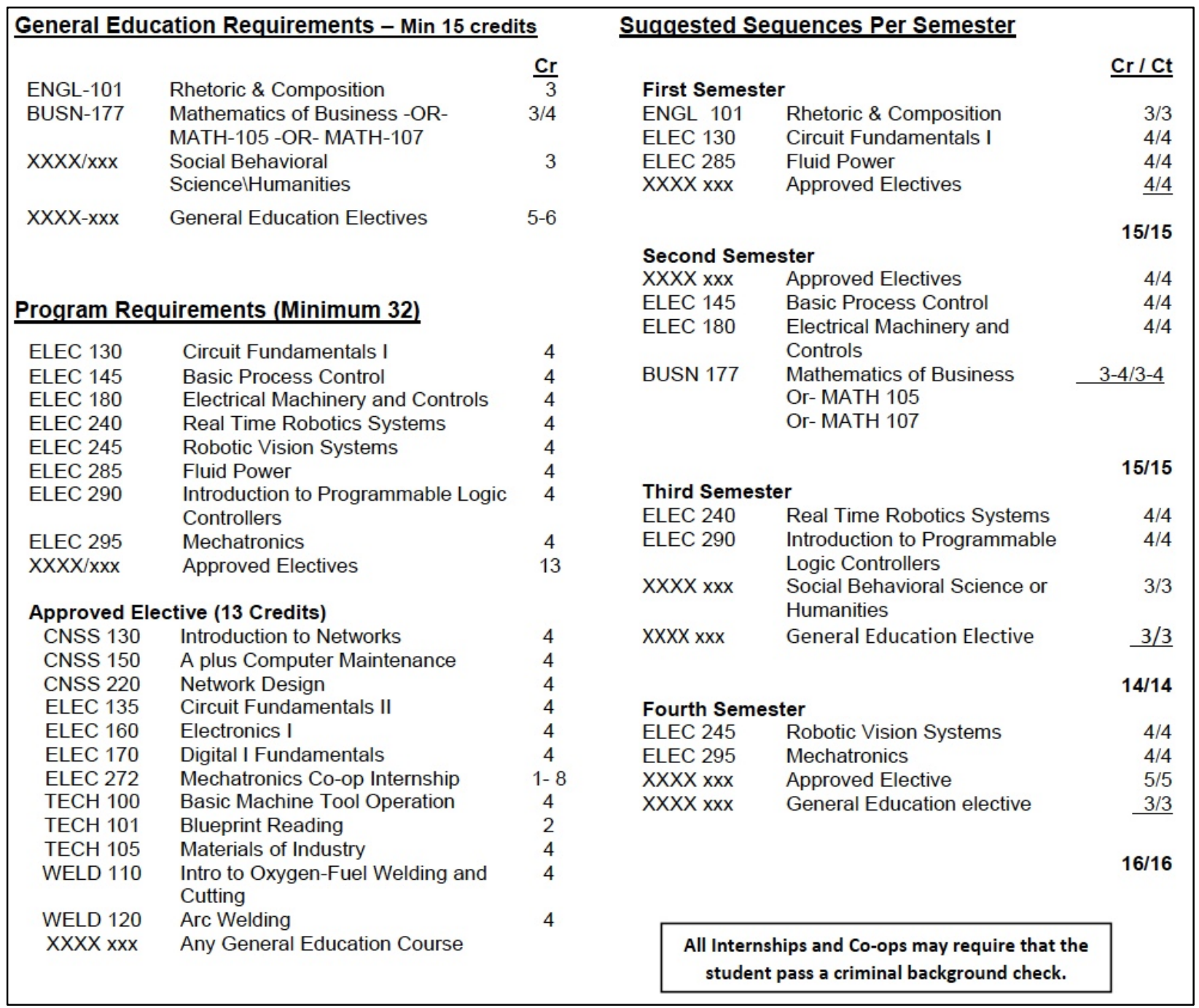

Figure 2: Course Overview of the Mechatronics and Robotic Systems Associate Degree 


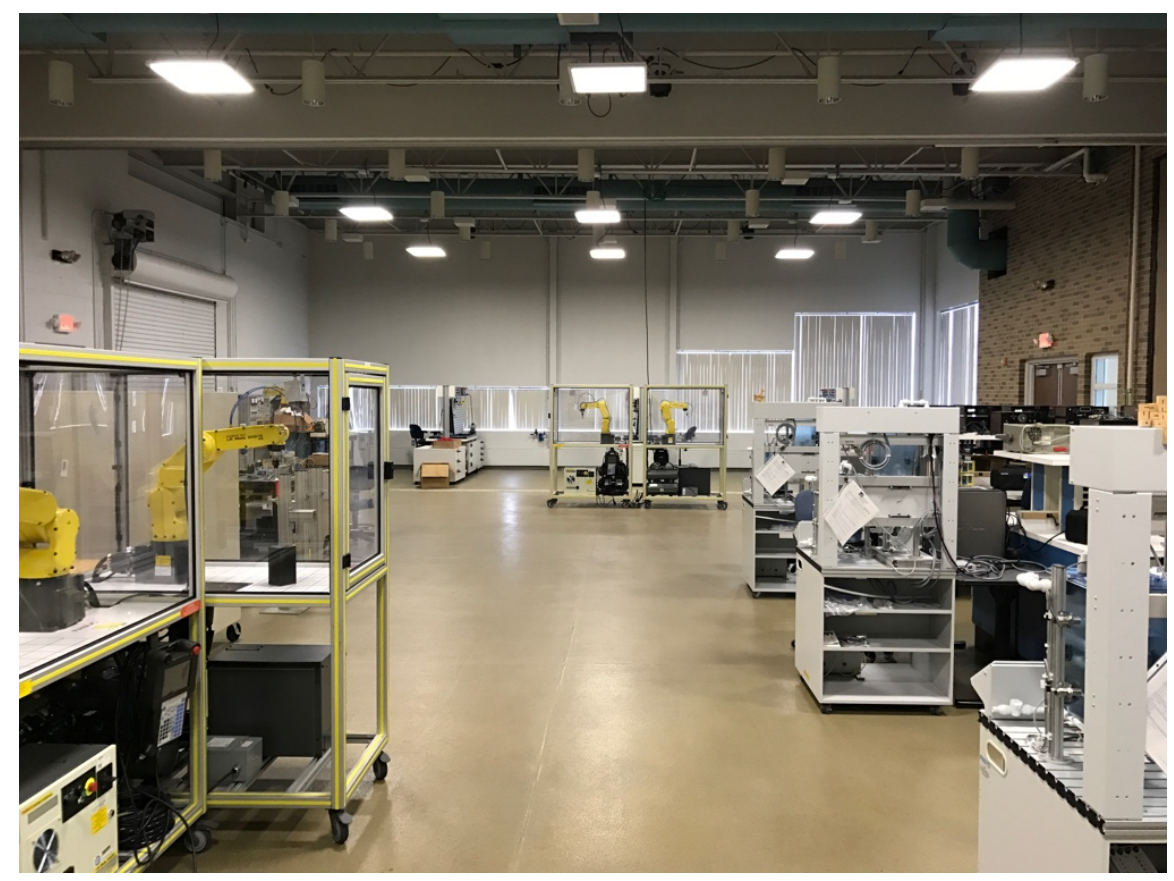

Figure 3: A view of XXXX College's new Mechatronics and Robotics Lab

\section{RobotRun Software}

Another aspect of the grant partnership between Bay College and Michigan Tech University is the development of robotics simulation software, titled RobotRun (Figure 4). This software has been fully developed and will be available for demonstration to conference attendees. The software simulates the programming and operation of a robotic arm, allowing students to craft programs and test them from the comfort of

their own home and without taking up valuable time on an actual robot. Labs that have been codeveloped by Bay College and Michigan Tech University faculty also provide exercises for students to complete that teach them about common programming mistakes and the proper technique to perform certain actions ${ }^{3}$.

\section{Initial Results of Non-Credit Workshops}

Another significant aspect of this project was the development and offering of non-credit workshops. These workshops were designed to target three separate groups: industry personnel, other educators at both the postsecondary and K-12 levels, and K-12 students. During the first year of the grant, a workshop aimed at other postsecondary educators was offered. A total of eight people attended this initial workshop, which was titled Revamping Robotics Education to Meet $21^{\text {st }}$ Century Workforce Needs. The primary idea behind the workshop was that there is a significant need for industrial certification programs in robotics, since it is increasingly used across industry sectors to improve production throughputs while maintaining product quality.

The benefits of robotics, however, depend upon workers with up-todate knowledge and skills to maintain and use existing robots, enhance future technologies, and educate users. It is therefore critical that education efforts respond to the demand for robotics specialists by

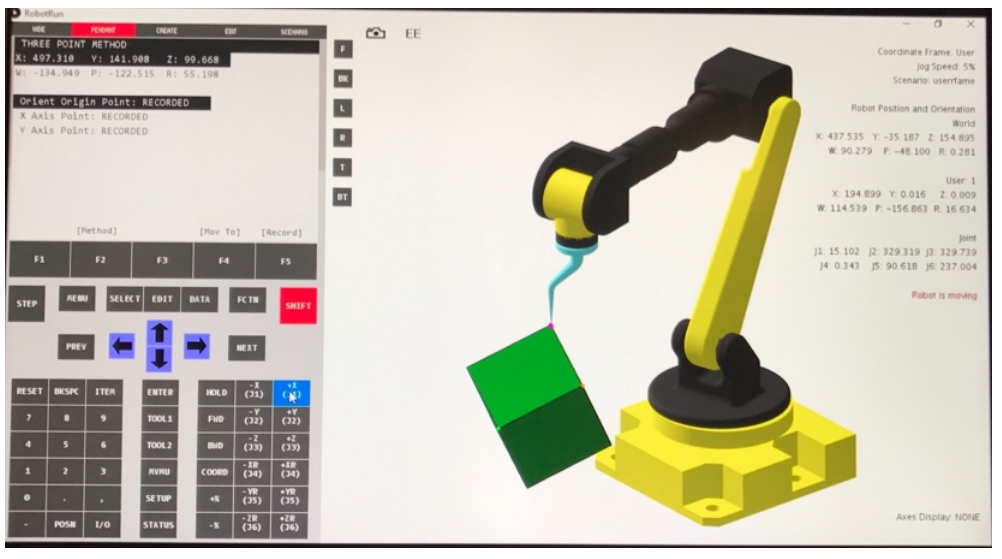

Figure 4: A screenshot of the RobotRun software 
offering courses and professional certifications in robotics and automation. In an effort to help meet this need, the workshop introduced participants to new approaches for teaching industrial robotics to match industry needs and provide a replicable model for programs around the US.

The workshop had a maximum class size of 12 and offered a stipend of $\$ 500$ to attendees to offset their time and travel thanks to available grant funds. However, despite this incentive, several people either did not show up for the workshop or canceled at the last minute, bringing the final attendance count to just eight participants. It was therefore decided that a good practice might be to charge attendees a $\$ 200$ deposit at the time of registration, to be returned to them with the additional $\$ 500$ stipend once they successfully attend. This strategy was attempted when Bay College offered their first version of this workshop in December 2016. Unfortunately, attendance results were not improved. A total of just four participants made it to the workshop, despite a total of nine being registered. Incidentally, all five who dropped the course did so before paying the registration fee. When queried, reasons given for failing to attend included personal, professional, and travel-related issues. Those who did attend the workshop had positive comments, with one individual actively trying to set up a partnership between his home university and Bay College as a result of his visit. Since one primary motivator for faculty participation in professional development events is scheduling it at a time in which the faculty member is not obligated to their regular duties ${ }^{4,5}$, and given the remote and wintery local of Bay College, next year's strategy will be to hold the workshop during the spring or summer months. The idea behind this approach is that potential registrants will be less busy and more likely to travel to the area when the weather is nice. Furthermore, crafting our marketing efforts to demonstrate how attendance will directly impact attendees' teaching excellence could attract more participants, since this too has been shown to be a strong motivating factor in professional development participation. ${ }^{4,5}$

Another non-credit workshop with much better attendance success was that which was aimed at K-12 students. This workshop was held on a Friday and attendees were excused from their regularly scheduled high school classes. The class ran completely full at 12 participants. In order to recruit participants, area high school instructors from several local schools were asked to invite their best students to the workshop, ensuring that those in attendance stood to benefit from the curriculum and also served as strong possible future college students. At the workshop, participants learned basic principles of industrial robots, including topics on robotic safety, basic mechanics and controls, robotic frames, and programming architecture. Hands-on activities that were age- and skill-appropriate for high school students taught them the basic concepts of optimal robot programming and manipulation utilizing industrial robotics. Students were introduced to basic programming functions and taught how to optimize a robotic path to conduct a simulated industrial task. Utilizing the RobotRun simulation software developed under the grant, students were able to play games and conduct basic programming tasks to simulate the robotically controlled process. Again, feedback received was very positive and the day camp will be offered again next year to a new group of students.

\section{Other Developments and Lessons Learned}

One of the most important steps taken at Bay College this year was to send its primary faculty member to receive training and certification from Integrated Systems Technologies (IST). This 
training not only prepared him to teach the courses now offered at Bay College, but also enables the institution to offer that same certification to its students and non-credit workshop participants. Given the limited number of locations available that offer this certification, our hope is that this training will pay off in the form of increased participation at workshop events in the future.

Another important lesson learned by the two partnering institutions this year was that all duties between the parties need to be clearly delineated and understood. While all grant deliverables were completed as planned, there was some confusion as to which specific pieces of curriculum were to be developed by Bay College and which pieces were to be developed by Michigan Tech University. This led to a certain amount of frustration and duplication of effort, so a meeting was scheduled at the beginning of year two to very clearly outline the expected deliverables of both parties before the year began. This seems simple, but has been an important takeaway of the development of this partnership thus far and is recommended for other institutions looking to form similar partnerships elsewhere. Partners should clearly state which curriculum will be developed by each party and supply deadlines for its completion. By taking the time to set up shared goals and ensure each partner fully understands the vision of what the partnership represents, the likelihood of partnership success is increased. ${ }^{6}$ Ideally, the goals of the partnership should become the focus of each party, rather than the individual goals of the partnering institutions. ${ }^{7}$

Lastly, promoting the improvements made under this partnership has been an important aspect of the work and has helped to raise awareness of the benefits of the community college and university partnership, as well as the importance of education in the skilled trades. The governor of Michigan visited the Bay College campus to tour through the new mechatronics and robotic systems laboratory, among others, and even mentioned one of the college's programs that he visited during his State of the State speech. The director of the state's Talent Investment Agency also visited the campus and was thoroughly impressed by the opportunities the program makes available to students, stating an interest in additional partnerships in the future between the college and the agency. Taking advantage of opportunities to showcase the work being performed under the grant and partnership is another critical step for institutions looking to replicate this model.

\section{Next Steps}

Now that the academic curriculum and non-credit workshops have been developed, much of the work in the coming year will be aimed at increasing enrollment and participation in these courses. Continuing to promote the program, both to increase enrollment and to encourage similar partnerships and programs elsewhere, will also be a primary focus. New lectures will be developed relating to robotic vision systems and certifications will be offered for robot operations and the use of robotic simulation software. Raising awareness of and encouraging educators to use the RobotRun software is also a focus of the coming year. Ultimately, the goal of this partnership and program is to elevate the quality of mechatronics and robotic systems education, and to improve this industry and our nation as a result. Therefore, distributing this software, sharing the lectures/labs that are developed, or simply talking to other schools about 
the benefits of a community college and university partnership are all important steps moving forward. 


\section{Bibliography}

${ }^{1}$ Upper Peninsula Travel and Recreation Association. (2016). Michigan's Upper Peninsula: Choose Your Path. Retrieved from Upper Peninsula Travel and Recreation Association: http://www.uptravel.com/groups-24/\#sect-62

${ }^{2}$ Delta Chamber of Commerce. (2016, May 2). About our area. Retrieved from Delta Chamber of Commerce: http://www.deltami.org/?aboutourare

${ }^{3}$ XXXX University. (2017). University, community college \& industry partnership: Revamping robotics education to meet $21^{\text {st }}$ century workforce needs:

http://www.cs.mtu.edu/ kuhl/robotics/

${ }^{4}$ Burdick, D., Doherty, T., \& Schoenfeld, N. (2015). Encouraging faculty attendance at professional development events. To Improve the Academy, 34(1), 39. Retrieved from http://cmich.idm.oclc.org/login?url=http://search.proquest.com.cmich.idm.oclc.org/docvi ew/1871573310?accountid=10181

${ }^{5}$ Lian, X. (2014). Factors that motivate faculty to participate in professional development activities (Order No. 3581491). Available from ProQuest Dissertations \& Theses Global: Social Sciences. (1584502030). Retrieved from http://cmich.idm.oclc.org/login?url=http://search.proquest.com.cmich.idm.oclc.org/docvi ew/1584502030?accountid=10181

${ }^{6}$ Eddy, P. (2010). Partnerships and collaboration in higher education. ASHE Higher Education Report, 36(2), 1-115. doi:10.1002/aehe.3602

${ }^{7}$ Shinners, K. D. (2006). Follow the leader: Project structure and leadership roles in a grant supported collaboration. International Journal of Educational Management, 29(3), 206214. 